\title{
PANDEMIA DA COVID-19: POSSIBILIDADES PARA DEMOCRATIZAÇÃO DA EDUCAÇÃO A DISTÂNCIA EM PROCESSO DE INCLUSÃO MUSICAL DIGITAL
}

\author{
COVID-19 PANDEMIC: POSSIBILITIES FOR DEMOCRATIZING DISTANCE \\ EDUCATION IN THE DIGITAL MUSICAL INCLUSION PROCESS
}

COVID-19 PANDEMIA: POSIBILIDADES DE DEMOCRATIZACIÓN DE LA EDUCACIÓN A DISTANCIA EN EL PROCESO DE INCLUSIÓN DE LA MÚSICA DIGITAL

\section{Paulo Eduardo Mauál, Gunnar Glauco De Cunto Carelli Taets ${ }^{2}$}

Resumo - Trata-se de um relato de experiência sobre um processo de inclusão musical digital para adultos cegos ou com baixa visão do Projeto Música Transformando Vidas (PROMUVI) realizado na Baixada Santista, São Paulo, durante a pandemia de COVID19. A maioria dos participantes do projeto, relatou vontade de continuar com as aulas virtuais após o final da pandemia, mesmo com os problemas de delay, reverberação, quedas de internet o que muito dificultou a apreciação musical do grupo. Novas formas de ensinar e aprender aumentam a diversidade das maneiras pelas quais se transmite música e inclusão. Este é um fenômeno que pode ser observado nesse tempo peculiar de pandemia. E o mais importante durante a realização desse projeto de forma virtual foi o "fazer música". Pode-se dizer que o PROMUVI demonstrou o musicking durante seus ensaios, também entendido como musicalidade em ação que permite explorar a diversidade de relações humanas. Que a estreita e desafiante relação estabelecida entre as Tecnologias da Informação e Comunicação (TIC), o Ensino à Distância e a inclusão digital, realce a necessidade constante de construirmos novas formas de práticas educacionais e musicais com espaço para o valor que esse fazer musical tem na vida dos participantes. O PROMUVI continuará com os encontros virtuais, buscando pessoas Brasil afora como forma de inclusão musical, desenvolvimento humano e proporcionando o aprimoramento de profissionais que queiram trabalhar com pessoas com deficiência visual e TIC.

Palavras-Chave: inclusão musical digital, acessibilidade, deficiência visual, educação à distância.

\footnotetext{
${ }^{1}$ Mestre em Comunicação Acessível, Escola Superior de Educação e Ciências Sociais do Instituto Politécnico de Leiria, Portugal.Especialista em Educação à Distância pela Universidade Federal Fluminense. Pesquisador do Grupo de Pesquisa em Música e Musicoterapia da UFRJ (GEPEMUSA/CNPQ). http://lattes.cnpq.br/6261225970889559

${ }^{2}$ Doutor em Ciências, Musicoterapeuta pelo Conservatório Brasileiro de Música. Professor Adjunto do Departamento de Enfermagem da Universidade Federal do Rio de Janeiro. Coordenador do Grupo de Pesquisa em Música e Musicoterapia da UFRJ (GEPEMUSA/CNPQ). http://lattes.cnpq.br/7530991449657861
} 
Abstract - This is an experience report on a digital music inclusion process for blind or low vision adults from the Music Transforming Lives Project (PROMUVI) held in Baixada Santista, São Paulo, during the COVID-19 pandemic. Most of the project's participants reported willingness to continue with virtual classes after the end of the pandemic, even with the problems of delay, reverberation, internet outages, which made the group's musical appreciation very difficult. New ways of teaching and learning increase the diversity of the ways in which music and inclusion are transmitted. This is a phenomenon that can be observed in this peculiar time of pandemic. And the most important thing during the realization of this project in a virtual way was "making music". It can be said that PROMUVI demonstrated musicking during its rehearsals, which can also be understood as musicality in action that allows exploring the diversity of human relationships. That the close and challenging relationship established between Information and Communication Technology (ICT), Distance Learning and digital inclusion, highlights the constant need to build new forms of educational and musical practices with space for the value that this musical making has in the lives of the participants. PROMUVI will continue with virtual meetings, seeking people from all over Brazil as a form of musical inclusion, human development and providing the improvement of professionals who want to work with people with visual impairments and ICT.

Keywords: digital musical inclusion, accessibility, visual impairment, distance education.

Resumen - Este es un informe de experiencia sobre un proceso de inclusión musical digital para adultos ciegos o con baja visión del Proyecto Música Transformando Vidas (PROMUVI) realizado en la Baixada Santista, São Paulo, durante la pandemia de COVID-19. La mayoría de los participantes en el proyecto se mostraron dispuestos a continuar con las clases virtuales una vez finalizada la pandemia, incluso con los problemas de retraso, reverberación y caídas de Internet que dificultaban enormemente la apreciación musical del grupo. Las nuevas formas de enseñanza y aprendizaje aumentan la diversidad de formas de transmitir e incluir la música. Este es un fenómeno que se puede observar en este peculiar momento pandémico. Y lo más importante durante la realización de este proyecto de forma virtual fue el "hacer música". Se puede decir que PROMUVI demostró en sus ensayos el musicking, entendido también como musicalidad en acción que permite explorar la diversidad de las relaciones humanas. Que la estrecha y desafiante relación que se establece entre las Tecnologías de la Información y la Comunicación (TIC), la Educación a Distancia y la inclusión digital, pone de manifiesto la constante necesidad de construir nuevas formas de prácticas educativas y musicales con espacio para el valor que este hacer musical tiene en la vida de los participantes. El PROMUVI continuará con los encuentros virtuales, buscando a personas de todo Brasil como forma de inclusión musical, desarrollo humano y proporcionando el perfeccionamiento de los profesionales que quieran trabajar con personas con discapacidad visual y TIC.

Palavra clave - inclusión musical digital, accesibilidad, discapacidad visual, educación a distancia

Revista Brasileira de Musicoterapia - volume 2 n² 29 ANO 2020 Mauá, P. E.; Taets,

G.G De C.C. Pandemia da Covid-19: possibilidades para democratização da educaçãoa distância em processo de inclusão musical digital (p.05 - 19) 


\section{Introdução}

Com o isolamento social a partir de 16 de março de 2020 por causa da pandemia do novo Coronavírus, a última aula presencial foi realizada dia 10 de março. Por se tratar de um grupo de risco da COVID19 (adultos com idade superior a 60 anos e pessoas com deficiência), por recomendação da Organização Mundial da Saúde (OMS) cancelamos as aulas e ficamos sem data de previsão de volta das aulas presenciais. $\mathrm{O}$ que fazer?

O projeto Música Transformando Vidas (PROMUVI), iniciado em 2009, utiliza método próprio baseado em exercícios técnicos de digitação na flauta, solfejo, memorização da sequência das notas, repetição e sem necessidade da musicografia braile.

O método mostra-se eficaz para pessoas com deficiência visual, parcial ou total, e com outras necessidades especiais, sejam em aulas de instrumentos específicos de orquestra. O que destaca o método do PROMUVI é a acolhida como ferramenta de cidadania e recuperação da autoestima.

A música como arte social envolve tocar com e para outras pessoas, como motivação e processo de aprendizado. A intranquilidade dos integrantes do PROMUVI perante a situação mundial de pandemia poderia ser dissolvida fazendo música, buscando dar conta de suas angústias durante os encontros virtuais.

Em tempos de pandemia, de isolamento e distanciamento social reconhece-se a importância do fazer musical para que a pessoa participe efetivamente do processo musical, seja ele terapêutico ou estético (Small, 1998).

A musicoterapia, que tem por objetivo processo terapêutico, e considera a música potente para transformar vidas enquanto uma ação humana nos ajudou a rever o que é música por meio do conceito de musicking.

Segundo Christopher Small (1998) musicking é envolver-se com uma performance musical do jeito que se pode, ou tocando (recitais), escutando, ensaiando ou praticando, compondo ou dançando. Pode-se dizer que o PROMUVI demonstra o 
musicking na prática de seus ensaios que pode ser também entendido como musicalidade em ação que permite explorar a diversidade de relações humanas.

Especificamente para os participantes do PROMUVI que são cegos, o musicking faz com que eles sejam participantes e atuantes no fazer musical. Segundo Bruscia (2000), "a arte é terapia, mesmo quando não é utilizada com esse propósito" (Bruscia, 2000, p.156).

A não obrigação da musicografia braile ocorre pelo grande número de pessoas no grupo com deficiência visual adquirida, ou seja, pessoas que perderam a visão, total ou parcialmente. O PROMUVI tem por objetivo a inclusão musical, e, um dos desafios da educação musical é incorporar Tecnologias de Informação e Comunicação (TIC) aos conceitos pedagógicos existentes em funcionamento nas aulas presenciais nas perspectivas didáticas do educador e expectativas do educando.

Como destaca Krüger (2006), as TIC chegam a inibir educadores e alunos, pois deparar com nova tecnologia altera a própria natureza humana. A chamada tecnofobia reflete o receio ao novo perante a tecnologia e o cuidado precisa ser redobrado com a aplicação de novas ferramentas na educação musical, "principalmente no que diz respeito à execução e apreciação musical”. (Krüger, 2006, p.77).

Alguns educadores musicais já passaram pela rica experiência de dar aulas para pessoas com deficiência visual em ambiente presencial. Infelizmente são poucos os que aceitam o desafio pedagógico no cenário nacional. Tudissaki (2019) destaca a falta de preparo de educadores musicais em lidar com estes alunos, principalmente em turmas heterogêneas, porque "é preciso compreender que cegos e pessoas com baixa visão tem necessidades diferentes umas das outras". (Santos \& Santiago, 2014, p. 5).

Com o surgimento da pandemia, os alunos do PROMUVI ficaram mais excluídos da sociedade e tivemos que nos reorganizar em tempo rápido. A alternativa seria transformar as aulas presenciais em virtuais.

Volta-se o pensamento para Parejo (2019) quando narra uma experiência com educandos de música que estavam sensíveis por dentro e fora e no encontro de angústias, havia um desejo de libertação frente à exaustão de livros e estudos. A educadora concluiu como conduzir as aulas: fazendo música. 


\section{PROMUVI em EAD - Um Relato de Experiência Memorável}

Mauá (2017) descreve que na lista de dicas de Swanwick para uma boa educação musical, os fracassos são mais importantes que os sucessos e que temos que ensinar no limite do risco. Por isso, o constante desafio de trabalharmos com inclusão musical, pois não existem professores que sabem tudo e sim "uma comunidade de aprendizes e a aula deve ser um momento de descobertas” como salienta Swanwick. (Mauá, 2017, p. 51).

Ser educador musical é tarefa gratificante, mas ser um bom profissional é enfrentar desafios, conhecer novas tendências, incessante aperfeiçoamento em métodos e metodologias. Compreender a importância do trabalho e principalmente amar e acreditar no "poder da música como agente transformador do indivíduo, buscando sempre se aperfeiçoar para uma crescente qualidade pedagógica e pessoal". (Santos \& Santiago, 2014, p. 1).

O ensino musical para cegos e pessoas com baixa visão continua um desafio para os educadores empenhados com a aprendizagem musical. Como salientam Santos \& Santiago (2014), chega a ser uma busca solitária e insana para adaptar aulas e materiais didáticos. Tudissaki (2019) lembra que no Brasil, o número de trabalhos científicos é relativamente pequeno e são poucas as instituições que promovem ensino musical dirigido especificamente para as pessoas com deficiência e na sua maioria, não estão estruturadas para um atendimento adequado eficaz.

O PROMUVI inova em método presencial para pessoas com deficiência visual e é chegada a hora de se reinventar em EAD, mas para isso precisa primeiro encantar os seus próprios educadores e viabilizar o acesso dos integrantes do projeto às aulas virtuais.

O período das primeiras aulas de EAD do PROMUVI foi de 31 de março à 8 de maio de 2020. Os participantes do projeto são: adultos com deficiência visual, total ou parcial, moradores da baixada santista (SP), um coordenador/regente/professor, cinco docentes, 23 alunos ativos em aulas presenciais. 


\section{Enfim, a primeira tentativa}

As aulas de EAD do PROMUVI iniciaram em 31 de março, o mesmo dia da semana da aula presencial (terça-feira) para não haver mudança radical na agenda dos integrantes. A aula presencial da orquestra do PROMUVI é realizada em duas horas, das $9 \mathrm{~h}$ às $11 \mathrm{~h}$, com coffee break de dez minutos. Resolvemos reduzir a aula virtual para uma hora.

A aula iniciou meia hora antes, com acolhida, instrução de uso e testes de áudio e vídeo. Iniciamos mantendo o método das aulas presenciais: aquecimento do corpo e instrumento, solfejo das melodias com acompanhamento da harmonia (bandolim do professor), explicações técnicas sobre digitação das notas, depois execução da melodia pela flauta doce dos alunos e ao final de cada melodia estudada, pausa para dúvidas gerais. Os integrantes depararam-se pela primeira vez com a novidade virtual do efeito de delay (atraso do som) e a reverberação (persistência do som, mesmo depois de emitido; eco). Logo, havia a necessidade de maior concentração no que estavam executando. Foram tocadas seis melodias no primeiro dia. Alguns integrantes não conseguiram entrar no programa Skype e cuidamos particularmente de cada um após o término da aula.

A primeira aula contou com a presença de 11 pessoas: o coordenador do projeto, um docente cego (professor de flauta doce), um ouvinte normovisual, três pessoas com deficiência visual total (DV), uma pessoa com deficiência visual total e autismo (DVA), dois integrantes com baixa visão (BV) e dois alunos/voluntários normovisuais.

Considerando o grupo de alunos ativos das aulas presenciais de 23 alunos, sendo que do grupo apenas cinco alunos/voluntários não possuem deficiência, tivemos uma adesão abaixo do esperado. Para aumentar o interesse pela EAD os participantes entrariam em contato os alunos ausentes, com outras pessoas com deficiência visual e integrantes afastados do projeto. Outra sugestão: em vez de uma aula por semana, duas reuniões virtuais.

Antes da segunda aula, divulgamos via WhatsApp, Facebook (/musicatransformandovidas) e Instagram (@musicatransformandovidas), fotos e textos 
da realização da primeira aula de $\mathrm{EAD}$, convocando os alunos do projeto e interessados. Mesmo assim, o mesmo número de pessoas (11) compareceu à segunda aula, mas com dois integrantes que não haviam participado da primeira aula: uma aluna BV e um aluno com síndrome de Down (SD), afastado do projeto, morador da cidade de São Paulo. Com isso, então já tínhamos agregado 13 pessoas através das TIC.

Pessoas que conhecem o projeto indagaram por que não transmitíamos as aulas pela internet. Ao final da aula, os participantes aceitaram o desafio de transformar as aulas virtuais do PROMUVI em LIVEs, com a participação ao vivo dos usuários no Instagram e Facebook.

\section{As LIVES como democratização da inclusão digital musical}

No dia 7 de abril, o PROMUVI realizou a primeira LIVE, via Instagram e Facebook, com a participação de 15 integrantes: o coordenador, três docentes, quatro pessoas com DV, dois BV, um aluno DVA, um SD, dois integrantes e um ouvinte normovisual.

$\mathrm{Na}$ aula virtual de 9 de abril, iniciou-se o aprendizado de nova música: SMILE, de Charlie Chaplin. Posteriormente, foram enviados áudios no WhatsApp: um com o solo da melodia em bandolim e outro com o solfejo, para que pudessem relembrar a sequência das notas. Em seguida, foi enviado por e-mail o arquivo em texto (nas extensões DOC, DOCX e TXT) para que as pessoas com cegueira total "lessem" a sequência das notas pelo programa $\operatorname{DOSVOX}^{3}$ e os integrantes de baixa visão pudessem imprimir a "partitura de notas" em casa. Cabe ressaltar que os participantes que aparecem na imagem a seguir (Figura 1), autorizaram a sua divulgação por meio escrito.

\footnotetext{
${ }^{3}$ DOSVOX é um programa para PC que se comunica com o usuário através de síntese de voz, viabilizando, o uso de computador por pessoas com deficiência visual. Acessado em 6 de maio de 2020 no site http://intervox.nce.ufrj.br/dosvox/intro.htm

Revista Brasileira de Musicoterapia - volume 2 n² 29 ANO 2020 Mauá, P. E.; Taets,

G.G De C.C. Pandemia da Covid-19: possibilidades para democratização da educaçãoa distância em processo de inclusão musical digital (p.05 - 19)
} 


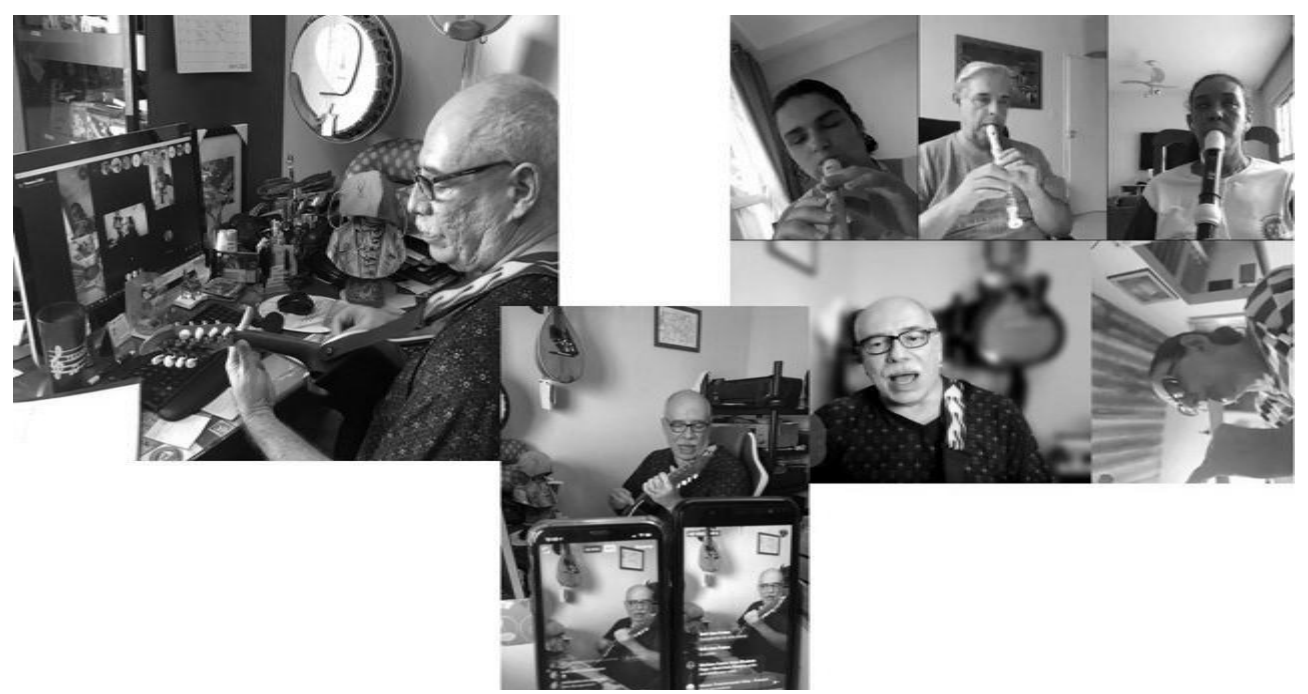

Figura 1. Registros fotográficos das LIVEs realizadas pelo PROMUVI

Fonte: autoria própria

Na LIVE no dia 14 de abril, 19 integrantes participaram com quatro dos cinco docentes do projeto.

\section{Docentes aderem ao EAD do PROMUVI}

O início das aulas de cordas (ukulele e violão) ocorre em 17/04 pela manhã e as aulas de canto coral no período da tarde. A partir do dia 28 abril, adesão dos professores de clarinete e flauta doce (docente cego).

A maior participação de alunos da EAD do PROMUVI foi na LIVE de 5 de maio com 22 integrantes e todos os docentes. A média de frequência nas aulas virtuais (incluindo as LIVEs) foi de 15,5 participantes, sendo a menor de nove pessoas no dia 9 de abril.

Através da divulgação nas principais mídias da internet, conseguimos destacar as LIVEs e o trabalho de EAD do projeto. Realizamos 11 aulas, sendo quatro LIVEs e em três delas o playlist foi divulgado antecipadamente para que a "plateia virtual" escolhesse música.

O musicoterapeuta, colaborador do projeto PROMUVI, lembra da afirmação de Small (1999) aos docentes que a essência da música não está nas obras musicais, mas na participação em desempenho, na ação social. Música é participar em qualquer 
capacidade de uma apresentação musical, e o significado da música está nas relações que são estabelecidas entre os participantes pelo desempenho.

\section{Resultados e Discussão}

Ao longo das aulas de EAD contamos com 28 integrantes, sendo 16 alunos ativos, seis docentes e sete ouvintes. Conseguimos resgatar dois alunos que abandonaram o projeto por barreira geográfica e fomos agraciados com três novos integrantes com DV, que conheciam o PROMUVI, mas não conseguiam frequentá-lo (vide Figura 1). Infelizmente, sete alunos ativos não participaram de nenhuma das aulas.

Após o período das LIVEs, foram enviados, de 8 a 13 de maio de 2020, dois tipos de questionários por WhatsApp e e-mail para descobrir as causas das não participações e como os envolvidos nas aulas virtuais se sentiram com a nova experiência.

As perguntas foram enviadas para os que participaram em mais de três aulas virtuais de orquestra: 19 alunos/integrantes (12 com DV, um com DVA, dois BV e quatro normovisuais), seis docentes e três ouvintes, totalizando assim 28 pessoas.

$\mathrm{Na}$ primeira pergunta, apenas um aluno com DV desconhecia o significado da sigla EAD. Para o questionamento de "estar gostando das aulas virtuais", a maioria informou que SIM e apenas duas (com DV) relataram que "mais ou menos".

Sobre as "dificuldades de acesso", duas pessoas optaram por "apenas inicialmente" e três escolheram "um pouco". Vale a pena destacar que 48,25\% (12 pessoas) dos alunos não tiverem dificuldades, sendo duas DV e uma BV. O docente cego quis destacar não teve dificuldade.

Pouco mais da metade dos usuários utilizaram smartphone para acesso às aulas $(54,57 \%)$, um pouco menos que $40 \%$ utilizou-se do computador e o restante de solução mista.

Sobre a preferência por "aula presencial ou EAD", seis alunos optaram pelas aulas virtuais, justamente os novos, os que não tem acesso às aulas no local do PROMUVI por problemas de deslocamento e mais uma aluna normovisual que 
frequenta as aulas presenciais, mas preferiu a flexibilidade de horário e comodidade das aulas em EAD.

Dois alunos com DV não se interessam por aulas virtuais (um destacou as aulas como "estressantes"), mas a maioria considerou a EAD importante dentro do projeto por motivos compilados abaixo:

"enfrentar novos desafios", "sair da zona de conforto e descobrir novas ferramentas de comunicação", "na ausência de aulas presenciais, a EAD é ótimo recurso";

"podemos tirar dúvidas sobre música em casa", "os dois tipos de aulas têm importância; uma complementa a outra";

"porque pode haver inclusão de pessoas e chamar pessoas novas para o projeto; atende às pessoas que não podem assistir às aulas presenciais"; "podemos rever os amigos e nos divertimos muito...".

\section{Descobrindo novos horizontes}

O uso da transdisciplinaridade surge como proposta da musicalização perante as TIC com o intuito de apoiar o integrante do projeto no entendimento e na descoberta da sua interioridade. Além de entrar na casa das pessoas, precisávamos despertá-los com carinho para um mundo novo, diferente e sem dor: o da inclusão digital musical, através da educação à distância.

A ideia de ir através das fibras de comunicações e das disciplinas, penetrando nas entrelinhas e nos significados ocultos, como Parejo (2019) define transdisciplinaridade, é justamente ultrapassar barreiras para transformar a realidade e assumir uma visão transformadora do mundo. O nome do projeto condiz com a proposta: Música Transformando Vidas para transformar mundos, do real para o virtual. A transdisciplinaridade oportuniza a "abertura do olhar para o mundo com uma nova lógica, aberta, ternária, conciliadora de elementos opostos, aparentemente inconciliáveis" (Parejo, 2019, p. 100).

Estava formatada a ideia de como conduzir a EAD do PROMUVI:com o olhar para o mundo de forma aberta, conciliadora e acolhedora; com as ferramentas de TIC mais acessíveis às pessoas com deficiência visual; com a missão de resgatá-las do meio da pandemia através do fazer música. 
Como lembra Santos \& Santiago (2014), a EAD é uma revolução não só no que diz respeito ao ensino mais democratizado, mas também em relação à acessibilidade de pessoas com deficiência. E acessibilidade é a língua a ser falada entre os homens.

A expressão EAD (educação à distância) vem se tornando um rótulo para classificar propostas e projetos distintos. A expressão é utilizada em sala de aula nas universidades, literatura especializada, em documentos oficiais e na mídia em geral. Além disso, pode representar diversas coisas ao mesmo tempo: formação continuada, educação aberta, autoensino, estudo on-line, e-learning, entre outras.

Segundo o Decreto Lei 2.494 de 1998 do MEC (BRASIL, 1998), a educação à distância é uma forma de ensino que possibilita a autoaprendizagem, com a mediação de recursos didáticos sistematicamente organizados, apresentados em diferentes suportes de informação (TIC), utilizados isoladamente ou combinados, e veiculados pelos diversos meios de comunicação.

Dessa maneira, a EAD se apresenta como caminho para a inovação e renovação educacional e como educadores devemos focar o nosso olhar e as nossas práticas no potencial da modalidade. Principalmente para as pessoas que estão distantes fisicamente do projeto musical (barreira geográfica de acessibilidade).

A EAD atual veio suprir a necessidade de flexibilidade de horário e duração do tempo de estudo, mas exige do educando ótima gestão de tempo e empenho como autodidata. Além disso, conhecimento das TIC, bom equipamento e internet, ou seja, acessibilidade.

No geral, a EAD promove a acessibilidade do aluno que mora distante dos centros de ensino e de pessoas com dificuldade de deslocamento, uma vez que, "o ato de aprender pode ser alcançado em qualquer lugar, independente da distância entre aluno e professor". (Costa, 2019, p. 31). O autor lembra ainda que os fóruns existentes em EAD não encontram metodologias e materiais didáticos focados nas pessoas com deficiência visual, apesar do imenso "poder de compartilhamento de informações e conhecimentos, nas mais distintas áreas, e como alternativa de aproximação das pessoas com deficiência visual com a aprendizagem de linguagens musicais" (Costa, 2019, p. $31)$.

Revista Brasileira de Musicoterapia - volume 2 n² 29 ANO 2020 Mauá, P. E.; Taets,

G.G De C.C. Pandemia da Covid-19: possibilidades para democratização da educaçãoa distância em processo de inclusão musical digital (p.05 - 19) 


\section{Barreiras Físicas e Acessibilidades}

Como Simão Neto (2012) cita, dentro das justificativas para implementação da EAD, além de vencer as barreiras físicas, podemos contar com a redução de custo das aulas presenciais, otimização de tempo e chance de descobrir novas formas de ensino e aprendizagem. $\mathrm{O}$ autor complementa que a EAD pode ser um caminho para "chegarmos a novas formas de ensinar e aprender, de acordo com paradigmas educacionais emergentes e propostas pedagógicas inovadoras”. (Simão Neto, 2012, p. 39).

Para o êxito da EAD do PROMUVI os docentes precisavam preparar as aulas e estarem prontos para solucionar casos de comunicação dos alunos. O bom educador precisa avaliar a melhor forma de como fará a mediação da aprendizagem, qual o tipo de avaliação a ser utilizado e elaborar os materiais didáticos adequados para as aulas virtuais.

A oposição à EAD, em termos de temores e resistências, vem de instituições, de opinião pública formada e até de profissionais receosos (tecnofobia), indo do puro preconceito a objeções mais políticas do que técnicas. É a velha resistência às mudanças.

A EAD do PROMUVI iria exigir dos educadores novas competências e habilidades, ampliação do "saber ouvir" e transmissão eficaz de conhecimento, só que remotamente. Nada diferente do que o educador precisa para que a aula presencial funcione ajustada dentro do que foi planejada.

Participar de uma performance musical, seja presencialmente ou no EAD, é como participar de um ritual cujas relações espelham e nos permitem explorar, afirmar e celebrar, os relacionamentos de nosso mundo como imaginamos que são e deveriam ser (Small, 1999). Logo, O EAD em música para cegos é possível quando feitas as adaptações necessárias e mudando de paradigma no entendimento da música, não como um substantivo, mas uma ação humana musicking.

\section{Considerações Finais}

Revista Brasileira de Musicoterapia - volume 2 n²9 ANO 2020 Mauá, P. E.; Taets,

G.G De C.C. Pandemia da Covid-19: possibilidades para democratização da educaçãoa distância em processo de inclusão musical digital (p.05 - 19) 
A descoberta da nova comunhão entre as pessoas e o projeto virtualmente, gerou alegria, prazer e a vontade de continuar trilhando as TIC como novas possibilidades, mesmo trazendo junto exigências para os envolvidos. É uma nova forma de pensar sobre a educação em si e o primeiro passo já foi dado. Quem sabe estamos abrindo portas para outras experiências, inclusive rumo à musicografia braile?

Afinal, Música é participar, com qualquer capacidade, em uma performance musical. Assim nos lembra Small (1999) que musicking é uma atividade em que todos os presentes estão envolvidos e por cujo sucesso ou fracasso todos os presentes têm uma responsabilidade. Isto não é apenas uma questão de compositores, ou mesmo performers, ativamente fazendo algo para o resto passivo de nós para contemplar. O que quer que esteja sendo feito, todos nós estamos fazendo juntos.

A maioria dos participantes do projeto relatou vontade de continuar com as aulas virtuais após o final da pandemia, mesmo com os problemas de delay, reverberação, quedas de internet e os latidos do cachorro do vizinho, o que muito dificultou a apreciação musical do grupo, entendendo que o fazer musical, a performance, ou seja, o musicking ainda que virtual, possibilita o alcance dos objetivos junto a essa população de pessoas com deficiência visual ávidos pelo aprendizado musical.

As LIVEs do PROMUVI alçaram voos inimagináveis: Alemanha, Portugal, França, Estados Unidos, nordeste do Brasil, interior de São Paulo, sul do país e todo o litoral paulista. Novas formas de ensinar e aprender aumentam a diversidade das maneiras pelas quais se transmite música e inclusão. É isso que tem acontecido nesse tempo peculiar de pandemia.

Que a estreita e desafiante relação estabelecida entre as TIC, o EAD e a inclusão digital, realce a necessidade constante de construirmos novas formas de práticas educacionais e musicais. O PROMUVI continuará com as aulas virtuais, buscando pessoas Brasil afora como forma de inclusão musical e proporcionando o aprimoramento de profissionais que queiram trabalhar com pessoas com deficiência visual e TIC. 
Falemos sempre a língua dos homens, da inclusão, pois o címbalo precisa do metal, da ciência e dos anjos. Jamais iremos conhecer todos os mistérios que envolvem as soluções e o amor. Tenhamos fé e perseverança para transformar vidas. Sem a inclusão musical digital, em tempos de pandemia COVID-19, nós nada seríamos.

\section{Referências}

Brasil. Decreto Lei $n^{\circ} 2.494$ de 10 de fevereiro de 1998. Regulamenta o Artigo 80 da LDB (Lei $n^{\circ}$ 9.394/96) de 20 de dezembro de 1996, Lei de Diretrizes e Bases da Educação Nacional. Disponível em http://portal.mec.gov.br/seed/arquivos/pdf/tvescola/leis/D2494.pdf. Acesso em 8 de maio de 2020.

Bruscia, Kenneth E (2000). Definindo Musicoterapia. Rio de Janeiro: Enelivros.

Costa, Luiz Fernando Navarro. (2019). EAD, música e inclusão: uma proposta de ensino e aprendizagem do violão popular na modalidade e distância para cegos. VII Encontro sobre Música e Inclusão. Universidade Federal do Rio Grande do Norte. Natal, RN. Disponível em https://emiufrn.files.wordpress.com/2019/08/029042 anais 2019 costa.pdf. Acesso em 19 de junho de 2019.

Krüger, Susana Ester (2006). Educação musical apoiada pelas novas tecnologias de informação e comunicação (TIC): pesquisas, práticas e formação de docentes.

Revista da ABEM. Porto Alegre, V. 14, 75-89, mar.. Disponível em http://www.abemeducacaomusical.com.br/revistas/revistaabem/index.php/revistaabe $\mathrm{m} /$ article/view/314/244. Acesso em 15 de abril de 2020.

Parejo, Enny (2009). Música e transdisciplinaridade: um caminho de interiorização. In: LIMA, Sonia Regina Albano (Org). Ensino, música \& interdisciplinaridade. Goiânia: Editora Vieira/Irokun Brasil. p. 95-126

Tudissaki, Shirlei Escobar (2009). Musicografia braille: um recurso para o ensino e aprendizagem musical de alunos cegos.In: LIMA, Sonia Regina Albano (Org). Ensino, música \& interdisciplinaridade. Goiânia: Editora Vieira/Irokun Brasil, p. 143-162.

Mauá, Paulo Eduardo (2017). Ensino de música para cegos sem braile: desafio ou loucura? Dissertação (Mestrado em Comunicação Acessível). Instituto Politécnico de Leiria. Escola Social de Educação e Ciências Sociais. Leiria, Portugal. Disponível em https://iconline.ipleiria.pt/bitstream/10400.8/2968/1/MauaPaulo MCA.pdf. Acesso em 30 de março de 2020.

Santos, Sueli Martins Leal \& Santiago, Glauber Lúcio Alves (2014). Recursos tecnológicos para o aluno de educação musical com baixa visão. Encontro de Pesquisadores em Educação à Distância. Simpósio Internacional de Educação à Distância. Universidade Federal de São Carlos. 

enped2016.ead.ufscar.br/ojs/index.php/2014/article/view/630. Acesso em 10 de abril de 2020.

Simão Neto, Antonio (2012). Cenários e modalidades de EAD. Ed. Rev. Curitiba: IESDE Brasil S.A.

Small, Christopher (1999). Musicking: the meanings of performance and listening. Middletown: Wesleyan University Press.

Recebido em 17 de outubro de 2020, aceito em 10 de novembro de 2020 